\title{
Details of blood changes in 32 patients with pancytopenia associated with long-term exposure to benzene
}

\author{
MUZAFFER AKSOY, KORAY DINÇOL, SAKIR ERDEM, TURAN AKGÜN \\ and GÜNÇAĞ DINÇOL \\ 2nd Internal Clinic of Istanbul Medical School, Capa, Istanbul, Turkey
}

\begin{abstract}
Aksoy, M., Dinçol, K., Erdem, Ş., Akgün, T., and Dinçol, G. (1972). Brit. J. industr. Med., 29, 56-64. Details of blood changes in 32 patients with pancytopenia associated with long-term exposure to benzene. A study was performed on 32 pancytopenic patients who had had longterm exposure to benzene. They had been subjected to high concentrations of benzene varying from 150 to 650 p.p.m. for from 4 months to 15 years. Apart from four, in whom the platelet count was normal, all had pancytopenia. As the bone marrow punctures of the pancytopenic patients showed a great variation from acellularity to hypercellularity, the patients were classified and studied according to the bone marrow findings.

Anaemia was macrocytic in 14, in three of whom a megaloblastic erythropoiesis was detected. The findings in some patients, such as mild reticulocytosis, hyperbilirubinaemia, erythroblastaemia, an increase in quantitative osmotic fragility and in faecal urobilinogen excretion as well as elevated serum LDH levels, suggested that these might be attributed to either increased haemolysis or the presence of ineffective erythropoiesis.

The $\mathrm{HbF}$ content in 20 out of 24 pancytopenic patients was above normal, ranging between $3.2 \%$ and $19.5 \%$, with a mean of $6.1 \%$. Mean values of $\mathrm{HbF}$ in groups with a hypoplastic, hyperplastic, and normoplastic bone marrow were essentially the same. The absolute amounts of $\mathrm{HbF}$ exceeded $400 \mathrm{mg} / 100 \mathrm{ml}$ in only 8 out of 24 patients, all of whom survived.

The $\mathrm{HbA}_{2}$ level was within normal limits in 21 out of 24 pancytopenic patients. It was definitely decreased in one and slightly so in three. These findings may suggest that $\mathbf{H b A}_{\mathbf{2}}$ occasionally shows a tendency to decrease in some patients with chronic benzene poisoning. The maturation arrest in both the myeloid and erythroid elements was the most frequently encountered finding.

In the bone marrow examinations, giant erythroid precursors varying from $9 \%$ to $\mathbf{7 2} \%$ were detected in two patients. In one of them, who also had hepatosplenomegaly, the development of preleukaemia was accepted. Varying mortality rates were estimated in the above-mentioned groups. The results obtained from treatment with steroids, androgens, phyto-haemagglutinin, and oxymetholone are also described.
\end{abstract}

Several haematological disorders, such as aplastic anaemia, leukaemia, leucopenia, thrombocytopenia, pancytopenia, acquired pseudo-Pelger-Huet anomaly, etc., have been attributed to chronic benzene poisoning.
In the last decade, in Istanbul and in other cities in Turkey, numerous cases of chronic benzene poisoning have been encountered among workers using benzene-containing adhesives in the manufacture of shoes and slippers. The unhygienic 
conditions of their workplaces have been described elsewhere (Aksoy et al., 1971a).

\section{Case material and methods}

The series comprised 32 patients with pancytopenia associated with long-term exposure to benzene. Of these, 25 patients were initially admitted to the haematology department of the 2nd Internal Clinic of Istanbul Medical School and, after discharge, were followed up by us for periods ranging from one to seven years. Five patients were followed up by us only in the outpatient department. One patient was seen in another hospital and another patient was followed up at our laboratory after discharge from a clinic in Istanbul.

The haematological methods were all standard. Platelet counts were performed with a phase-contrast microscope using the Brecher-Cronkite (1950) technique. Haemoglobin $F$ was determined by the method of Singer, Chernoff, and Singer (1951). Haemoglobin $\mathrm{A}_{2}$ was estimated quantitatively by DEAE-cellulose (DEAESephadex A, Medium, Anion exchanger, Pharmacia Uppsala, Sweden) chromatography and by starch gel electrophoresis, according to the methods of Huisman and Dozy (1961) and Aksoy and Erdem (1965). With these methods normal values for haemoglobin $\mathrm{A}_{2}$ range between 2 and $3 \%$ for the former and between 1.5 and $4 \%$ for the latter. G-6PD activity was determined either quantitatively or qualitatively by the methods of Gadsden and Cannon (1964) and Tönz and Betke (1962). The quantitative osmotic fragility tests before and after 24 hours' incubation at $37^{\circ} \mathrm{C}$ were performed by Dacie's (1960) method. Serum lactate dehydrogenase values were determined by the method of Wroblewski and LaDue (1955). Faecal urobilinogen was estimated by the method of Young, Davis, and Hogestyn (1949) using a comparator block. ${ }^{1}$ In this method, values for faecal uro-

${ }^{1}$ Manufactured by W. A. Taylor Co., Baltimore, Md, U.S.A. ${ }^{2}$ Draeger Gasspurgerat/Multi Gas Detector Mod.21/31 Lübeck, Germany. bilinogen are 50 to 300 Ehrlich units for $100 \mathrm{~g}$ of faeces. Concentrations of benzene vapour in the air of working environments of the patients were measured by a Draeger Multigas Detector. ${ }^{2}$

\section{Results}

Though the clinical features and haematological data for these 32 patients were generally similar, their bone marrow findings were different. Thus, the patients have been classified into four groups as follows:

Group 1 Pancytopenia with a hypoplastic or acellular bone marrow (cases 1 to 12 inclusive)

Group 2 Pancytopenia with a hyperplastic bone marrow (cases 13 to 19 inclusive)

Group 3 Pancytopenia with a normoplastic bone marrow (cases 20 to 31 inclusive)

Group 4 Pancytopenia with giant erythroid precursors, possibly as a finding of preleukaemia (case 32).

\section{Clinical and occupational findings}

The series consisted of 30 males and 2 females, ranging in age from 15 to 57 years, with an average of 32 years (Table 1).

Twenty-four patients worked in small workshops manufacturing shoes. Two worked in a box factory, another two manufactured objects made of leather, one made glues containing benzene, one was a car painter, one a radio repairman, and another a furniture maker. All were using benzene-containing materials as adhesives. The working conditions of all the patients were hardly good as their working places were unhygienic and poorly ventilated. The concentrations of benzene in their working environment ranged between 15 and 30 p.p.m. outside working hours and were recorded to reach 210 or,

TABLE 1

Comparison of Some Clinical Data in Four Groups

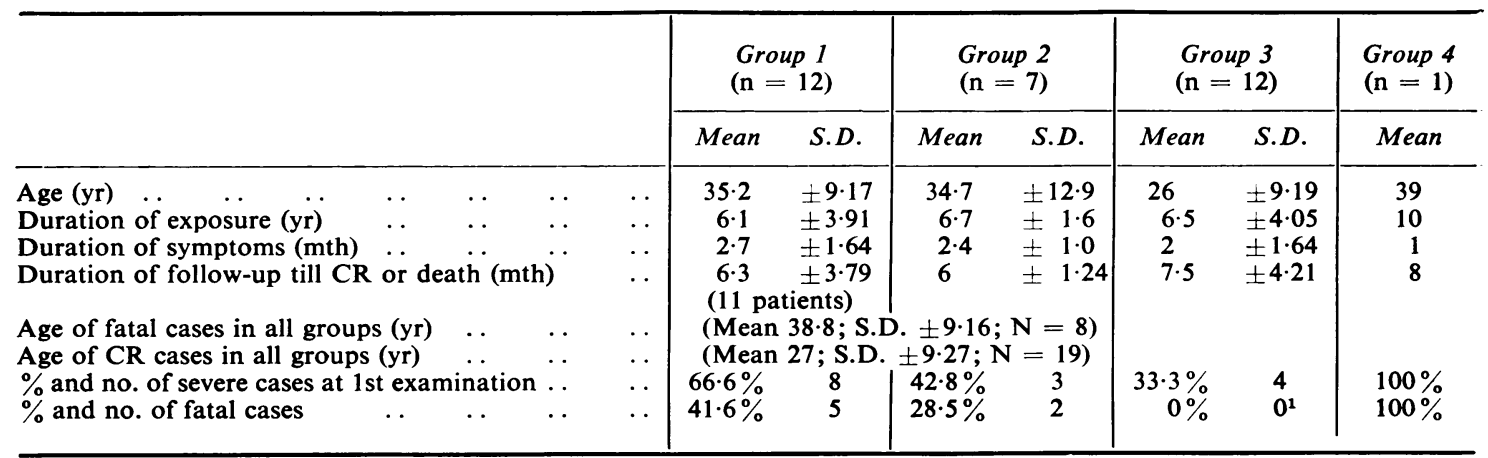

${ }^{1}$ One of the patients in this group was critically ill and refractory to all treatment when he was discharged. It is quite probable that he died

$\mathbf{C R}=$ complete recovery 
rarely, 640 p.p.m. when benzene-containing adhesives were being used. The period of exposure ranged from 4 months to 15 years. In two patients the period of exposure was less than one year, in 10 between one and five years, in 17 between 5 and 10, and in three more than 10 years. There was no significant difference in the duration of exposure between all four groups, the mean duration of exposure being $6 \cdot 1,6 \cdot 7,6 \cdot 5$, and 10 years respectively. On the other hand, although when first seen a moderate or severe pancytopenia was detected in most of the patients, the duration of symptoms attributable to pancytopenia before the first examination or admission was surprisingly very short, ranging mostly between one and three months. This may be explained by the insidious development of the disease. Five of the patients were symptomless and were discovered during a survey of workers using benzene-containing materials (Aksoy et al., 1971a).

Details of the clinical findings are shown in Table 2. They included signs and symptoms attributable to pancytopenia, such as lassitude, palpitations and dyspnoea on exertion, pallor, purpura, ecchymoses, epistaxis, and bleeding from the oral mucosae and from the gastrointestinal tract, particularly in association with secondary infections. In two patients severe and rare complications of secondary thrombocytopenia were detected, a fatal haemothorax and a haemorrhagic pleurisy. On the other hand, in two patients (cases 1 and 32) a marked or moderate hepatosplenomegaly developed during the course of the illness. Unfortunately, we were not able to perform a splenic puncture or necropsy in these two fatal cases. In one patient, a marked hepatosplenomegaly causing severe abdominal pains had developed nearly two weeks before death and the cause of the hepatosplenomegaly remained obscure. In the other case, group 4, the cause of the hepatosplenomegaly was possibly preleukemia, as will be explained below.

\section{Haematological and laboratory data}

Table 3 gives some important haematological findings for each group of patients.

Red blood cells Generally, the severity of anaemia was similar in all four groups, but some pancytopenic patients with a normoplastic bone marrow had higher values than those of the pancytopenic patients with hypoplastic or hyperplastic bone marrow. In the patients with hyperplastic or hypoplastic bone marrows, the mean reticulocyte counts were slightly increased.

Erythroblastaemia In six patients nucleated red cells were present in the peripheral blood, ranging between 1 and 8 per 100 WBC.

Quantitative osmotic fragility A quantitative test was performed in 20 out of 32 patients before and after 24 hours' incubation at $37^{\circ} \mathrm{C}$. It was normal in seven of them. A mild or moderate increase either before or after incubation was detected in the remaining 13 patients.

Fetal haemoglobin This was determined in 24 out of 32 patients. In the remaining eight patients, fetal

TABLE 2

Number of Patients Exhibiting the Described Signs and Symptoms among the 32 Pancytopenic Patients together With Outcome and Cause of Death

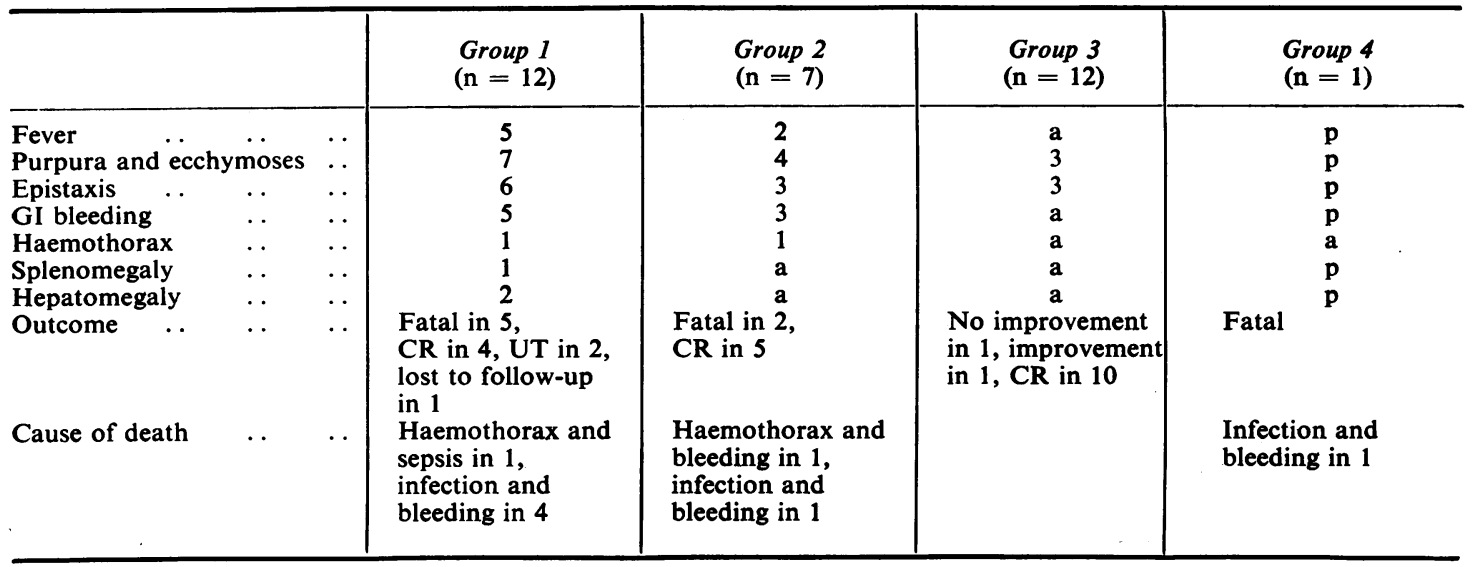

$\mathrm{CR}=$ complete recovery; $\mathrm{UT}=$ under treatment; $\mathrm{p}=$ present; $\mathrm{a}=$ absent 
TABLE 3

Some Haematological and laboratory Data in the 32 Patients

\begin{tabular}{|c|c|c|c|c|c|c|c|c|c|c|c|c|c|}
\hline & & & \multicolumn{3}{|c|}{ Group 1} & \multicolumn{3}{|c|}{ Group 2} & \multicolumn{3}{|c|}{ Group 3} & \multicolumn{2}{|c|}{ Group 4} \\
\hline & & & Mean & S.D. & $n$ & Mean & S.D. & $n$ & Mean & S.D. & $n$ & Mean & $n$ \\
\hline \multicolumn{3}{|l|}{ RBC $\left(10^{6} / \mathrm{mm}^{3}\right)$} & 2.03 & $\pm \quad 0.5597$ & 12 & 1.97 & $7 \pm \quad 0.402$ & 7 & $2 \cdot 22$ & \pm 1.035 & 12 & 1.60 & 1 \\
\hline $\mathrm{Hb}(\mathrm{g} \%)$ & & ${ }^{\circ}$ & $5 \cdot 4$ & $\pm \quad 1.215$ & 12 & 5.6 & \pm 0.755 & 7 & 5.9 & +2.66 & 12 & $4 \cdot 5$ & 1 \\
\hline $\mathrm{WBC} / \mathrm{mm}^{3} \quad \ldots$ & .. & . & 2250 & \pm 714 & 12 & 2310 & \pm 103 & 7 & 2310 & \pm 788 & 12 & 400 & 1 \\
\hline Reticulocytes $(\%)$ & & .. & 1.7 & $\pm \quad 1.3$ & 12 & $2 \cdot 6$ & $\pm \quad 1.67$ & 7 & 2.9 & $\pm \quad 1.42$ & 12 & 0 & 1 \\
\hline Platelets $\left(10^{3} / \mathrm{mm}^{3}\right)$ & $\ldots$ & . & $80 \cdot 2$ & \pm 71.6 & 12 & 59 & \pm 31.54 & 7 & $95 \cdot 5$ & \pm 51.71 & 12 & 10 & 1 \\
\hline Haematocrit $(\%)$ & . & .. & $18 \cdot 5$ & $\pm \quad 4.5$ & 12 & 20 & \pm 4.6 & 7 & $20 \cdot 8$ & \pm 10.04 & 12 & 19 & 1 \\
\hline $\operatorname{MCV}\left(\mu \mathrm{m}^{3}\right) \ldots$ & . & & 91 & $\pm \quad 5.38$ & 12 & $98 \cdot 2$ & $\pm 8 \cdot 1$ & 7 & 93 & \pm 6.32 & 12 & 118 & 1 \\
\hline MCHC (\%) & & .. & $30 \cdot 6$ & & 12 & 29 & $\pm \quad 6.24$ & 7 & $29 \cdot 2$ & $\pm \quad 5.38$ & 12 & 24 & 1 \\
\hline Lymphocytes (\%) & & .. & $43 \cdot 5$ & $\pm 14 \cdot 17$ & 12 & $36 \cdot 6$ & \pm 12.59 & 7 & $33 \cdot \overline{8}$ & \pm 17 & 12 & 64 & 1 \\
\hline $\mathrm{NRC} / 100 \mathrm{WBC}$ & & . & 0 & 0 & 12 & $1 \cdot 7$ & - & 7 & 0.08 & - & 12 & 2 & 1 \\
\hline Total bilirubin (mg & $\%)$ & .. & 1.05 & \pm 0.32 & 11 & 1.09 & \pm 0.51 & 7 & 0.85 & $\pm \quad 0.72$ & 9 & $1 \cdot 5$ & 1 \\
\hline Serum iron $(\mu \mathrm{g} \%)$ & & & 126 & \pm 53.35 & 7 & 140 & \pm 70 & 6 & 170 & \pm 56.84 & 7 & 190 & 1 \\
\hline Fetal Hb (\%) & & & $5 \cdot 4$ & \pm 2.09 & 7 & $5 \cdot 8$ & $\pm \quad 4.7$ & 6 & 6.9 & $\pm \quad 4.4$ & 11 & $x$ & 0 \\
\hline \multirow{2}{*}{\multicolumn{3}{|c|}{$\begin{array}{l}\text { Total fetal } \mathrm{Hb}(\mathrm{mg} / 100 \mathrm{ml}) \\
\text { Haemoglobin } \mathrm{A}_{2} \\
\text { (Sephadex Chromatography) } \\
\text { Haemoglobin } \mathrm{A}_{2} \text { (Starch- }\end{array}$}} & 365 & $\pm 175 \cdot 2$ & 7 & $308 \cdot 2$ & $\pm 193 \cdot 6$ & 6 & 696 & $\pm 619 \cdot 8$ & 11 & $\mathbf{x}$ & 0 \\
\hline & & & $2 \cdot 26$ & \pm 1.03 & 7 & $2 \cdot 15$ & \pm 0.55 & 2 & $2 \cdot 1$ & \pm 0.55 & 8 & $\mathbf{x}$ & 0 \\
\hline \multicolumn{3}{|c|}{$\begin{array}{l}\text { Haemoglobin } A_{2} \text { (Starcn- } \\
\text { gel electrophoresis) .. }\end{array}$} & $\mathbf{0}$ & & 0 & $2 \cdot 4$ & \pm 0.52 & 4 & $2 \cdot 5$ & \pm 0.53 & 3 & $\mathbf{x}$ & 0 \\
\hline \multicolumn{3}{|l|}{$\begin{array}{l}\text { Faecal urobilinogen } \\
\text { (Ehrlich } \mathrm{U} / 100 \mathrm{~g})\end{array}$} & 329 & $\pm 159 \cdot 5$ & 6 & 510 & $\pm 364 \cdot 4$ & 4 & 428 & \pm 176.9 & 7 & $\mathrm{x}$ & 0 \\
\hline \multirow{2}{*}{\multicolumn{3}{|c|}{$\begin{array}{l}\text { Serum LDH (Wroblewsky U) } \\
\text { Quantitative osmotic } \\
\text { fragility }\end{array}$}} & 484 & $\pm 225 \cdot 7$ & 7 & 0 & - & 0 & 609 & $\pm \mathbf{2 8 7 \cdot 7}$ & 3 & 840 & 1 \\
\hline & & & & & & & & & & & & & \\
\hline \multirow{2}{*}{\multicolumn{2}{|c|}{ before incubation }} & . & \multirow{2}{*}{\multicolumn{3}{|c|}{$\begin{array}{l}\text { Slightly or moderately } \\
\text { increased in } 3 \text { out of } 6\end{array}$}} & \multirow{2}{*}{\multicolumn{3}{|c|}{$\begin{array}{l}\text { Slightly increased } \\
\text { in } 4 \text { out of } 6 \\
\text { Moderately increased } \\
\text { in } 1 \text { out of } 6\end{array}$}} & \multirow{2}{*}{\multicolumn{3}{|c|}{$\begin{array}{l}\text { Slightly increased } \\
\text { in } 2 \text { out of } 7 \\
\text { Slightly increased } \\
\text { in } 3 \text { out of } 7\end{array}$}} & & 1 \\
\hline & & . & & & & & & & & & & Normal & 1 \\
\hline \multicolumn{3}{|l|}{ G-6PD screening test } & \multicolumn{3}{|c|}{$\begin{array}{l}\text { Positive in } 9 \text {, } \\
\text { negative in } 1\end{array}$} & \multicolumn{3}{|c|}{ Positive in all } & & Positive & 1 \\
\hline
\end{tabular}

S.D. = standard deviation; $\mathrm{n}=$ number $; \mathrm{x}=$ not performed

haemoglobin estimations were not performed because of large numbers of blood transfusions. In 20 patients $\mathrm{HbF}$ was increased (mean $6 \cdot 14 \%$; range 3.2 to $19.5 \%$ ) and was within normal limits in the remaining four. However, the absolute amount of fetal haemoglobin exceeded $400 \mathrm{mg} / 100 \mathrm{ml}$ in only 8 of the 24 .

Haemoglobin $\mathbf{A}_{2}$ In 21 out of 24 patients, $\mathrm{HbA}_{2}$ values were found within normal limits. The $\mathbf{H b A}_{2}$ was definitely decreased in one patient to $1.5 \%$ and slightly in two patients to 1.9 and $1.95 \%$. In addition, in one patient of group $3 \mathrm{HbA}_{2}$ like $\mathrm{HbF}$ was within normal ranges on admission $(2 \cdot 2 \%)$ but three months later, following a considerable haematological improvement, it had decreased to $1.95 \%$.

White blood cells All the patients investigated had pancytopenia. Eight patients had a relative lymphocytosis, ranging from 50 to $78 \%$. In the remainder, there was an absolute lymphopenia. A mild increase in monocytes, ranging from 9 to $13 \%$, was detected in four patients. One patient in group 1 showed a marked Pelger-Huet anomaly following complete recovery $(53 \%$ of the leucocytes had one or two lobes). This abnormal feature persisted for two and a half years after clinical and haematological recovery. Neither his mother nor one of his sisters showed a similar leucocyte anomaly.

Platelets A severe or moderate thrombocytopenia was found in all except four patients. One of the four patients with an abnormal platelet level had a severe anaemia and leucopenia which were refractory to all treatment, and his platelet levels, determined several times during a one-year period, were always found to be within normal limits. In the blood smears of the patients with low levels of platelets, giant or morphologically abnormal platelets were detected.

Bilirubinaemia A mild hyperbilirubinaemia was found in 8 out of 28 patients studied.

Serum lactate dehydrogenase activity In 6 out of 11 pancytopenic patients the serum lactate dehydro- 
genase activity was significantly increased, ranging between 600 and 930 Wroblewski units. In one patient, the LDH level returned to normal following the improvement of the haematological state. In four patients with an elevated LDH level there were findings of increased haemolysis, so the increase in LDH activity may be attributed to the presence of a haemolytic component. On the other hand, in a patient in group 4 the increased level of activity of this enzyme may be explained by a state of preleukaemia.

Life span of erythrocytes The life span of the red blood cells was measured by the ${ }^{51} \mathrm{Cr}$ method in one patient only and was moderately shortened-21 to 28 days.

Faecal urobilinogen $A$ mild or moderate increase in the excretion of faecal urobilinogen was observed in 9 out of 17 patients.

G-6PD activity Only one out of 22 patients studied showed G-6PD deficiency.

Serum electrophoresis and liver function tests

Serum electrophoresis and liver flocculation tests such as thymol turbidity and alkaline phosphatase levels were determined in all the patients. The results were within normal limits. Only in one patient, in group 3, did the bromsulphalein test show a $23 \%$ retention. In this patient the results of pyruvic and glutamic oxalacetic transaminase activities, thymol turbidity, and prothrombin times were within normal range. Following complete recovery the results of the bromsulphalein test remained unchanged.

\section{Bone marrow}

Table 4 gives the results of bone marrow punctures in each group. In three patients in group 1 , repeated bone marrow punctures were performed at different sites and no material was obtained. The bone marrows of these patients were considered to be acellular. In 12 patients, bone marrows were normocellular, in 9 hypocellular, and in the remaining 7 hypercellular. The bone marrow findings of a patient in group 4 were strongly suggestive of preleukaemia. A maturation arrest in the myeloid series was observed in 15 patients and in the erythroid series in 9 patients. A mild or moderate megaloblastic erythropoiesis was observed in three patients from groups 1,2 , and 4 in whom megaloblasts ranged between 4 and $22 \%$.

In the one patient in group 4, giant erythroid precursors comprising 38 to $72 \%$ of the nucleated cells were found. In this patient these erythroid precursors appeared during the course of the disease, lasting eight months, and persisted till death. Of the four bone marrow punctures, numerous giant erythroid precursors as well as those of normal size were detected in the last three. The cytoplasms of these elythıoid precursors were deeply basophilic, some resembling plasma cells. They sometimes showed bizarre forms and were usually in clusters. The chromatin network of the nuclei of these cells was fine and a number appeared to have two lobes. They often had one to four large nucleoli and they

\section{TABLE 4}

Bone Marrow Findings in the 32 patients

\begin{tabular}{|c|c|c|c|c|c|c|c|c|c|c|c|}
\hline & & & & \multicolumn{2}{|c|}{$\begin{array}{l}\text { Group } 1 \\
(\mathrm{n}=9)^{1}\end{array}$} & \multicolumn{2}{|c|}{$\begin{array}{l}\text { Group } 2 \\
(\mathrm{n}=7)\end{array}$} & \multicolumn{2}{|c|}{$\begin{array}{l}\text { Group } 3 \\
(\mathrm{n}=12)\end{array}$} & \multicolumn{2}{|c|}{$\begin{array}{l}\text { Group } 4 \\
(\mathrm{n}=1)^{3}\end{array}$} \\
\hline & & & & Mean & S.D. & Mean & S.D. & Mean & S.D. & Mean & S.D. \\
\hline \multicolumn{3}{|c|}{ 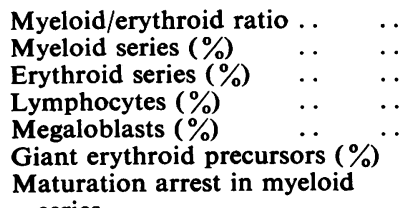 } & $\begin{array}{l}\ldots \\
\ldots \\
\ldots \\
\ldots \\
\\
\cdots \\
\ldots \\
\ldots\end{array}$ & $\begin{array}{l}1: 0.7 \\
39 \cdot 7 \\
26.2 \\
29 \cdot 7 \\
0.44 \\
0 \\
\\
\text { Present in } \\
\text { Present in } \\
\text { Present in } \\
\text { Present in }\end{array}$ & $\begin{array}{l} \pm 16.06 \\
\pm 11.09 \\
\pm 19.46 \\
\text { n.p. } \\
\text { n.p. }\end{array}$ & $\begin{array}{l}1: 2 \\
34 \cdot 7 \\
46 \\
8 \cdot 2 \\
3 \cdot 1^{2} \\
0 \\
\text { Present in } \\
\text { Present ir } \\
\text { Present ir } \\
\text { Present ir }\end{array}$ & $\begin{array}{l} \pm 14 \cdot 45 \\
\pm 7 \cdot 21 \\
\pm 6 \cdot 40 \\
\text { n.p. } \\
\text { n.p. }\end{array}$ & $\begin{array}{l}1: 1 \cdot 05 \\
46 \cdot 6 \\
38 \\
12 \cdot 3 \\
0 \\
0 \\
\\
\text { Present in } \\
\text { Present in } \\
\text { Present in } \\
\text { Present in }\end{array}$ & $\begin{array}{l} \pm 16.24 \\
\pm 13.03 \\
\pm 6.48\end{array}$ & $\begin{array}{l}1: 8 \cdot 3 \\
19 \cdot 7 \\
16 \cdot 5 \\
8 \\
8 \\
44 \cdot 5 \\
\text { Absent } \\
\text { Present } \\
\text { Absent } \\
\text { Present }\end{array}$ & $\begin{array}{l} \pm 29 \cdot 51 \\
\pm 8 \cdot 42 \\
\pm 3 \cdot 31 \\
\text { n.p. } \\
\text { n.p. } \\
\end{array}$ \\
\hline
\end{tabular}

13 patients with acellular bone marrow are not included in the calculation of the values

A megaloblastic erythropoiesis developed in one patient during the course of the disease

${ }^{3}$ In this patient four bone marrow punctures were performed and the mean values were calculated accordingly

n.p. $=$ not performed 
showed numerous mitotic forms. Unstained areas were also found in the cytoplasm of these giant erythroid precursors which sometimes strongly resembled promegaloblasts. As will be explained below, we are strongly inclined to consider these cells as a finding of preleukaemia. In this patient with numerous giant erythroid precursors, a megaloblastic erythropoiesis was present during the course of the illness, megaloblasts comprising 12 to $20 \%$ of the nucleated cells.

In the majority of the patients, a vacuolation in the myeloid and/or erythroid elements was observed.

\section{Outcome}

Eight of the patients died of complications of pancytopenia such as bleeding and/or secondary infection (Table 2). Of the 24 surviving patients, four were pancytopenic when last observed. One of these, in group 3 , required periodic blood transfusions.

\section{Treatment \\ Androgens Twelve patients, of whom five had hypoplastic, two had hyperplastic, and five had normoplastic bone marrows, 1eceived only andro- gens. Five of them were in a serious clinical and haematological condition. Of these patients, two with a hypoplastic and one with a hyperplastic bone marrow died.}

Steroid Steroids with androgens were used in seven patients, four with a hyperplastic and three with a normoplastic bone marrow. Only one patient with a hyperplastic bone marrow died during the treatment due to the complications of his severe condition.

Phytohaemagglutinin $^{1}$ Six patients, of whom three had hypoplastic bone marrow, two had hyperplastic bone marrow, and one was in a preleukaemic stage, received androgens, steroids, and PHA. In addition to this, in three patients, two with hypoplastic and one with normoplastic bone marrows, PHA was used parenterally, $50 \mathrm{mg}$ per day for 20 to 21 days. Two patients with a hypoplastic and one with a preleukaemic bone marrow died.

Oxymetholone One patient with a hypoplastic and two with a normoplastic bone marrow received oxymetholone. One patient with an acellular bone marrow died despite treatment. In another, in group 3 , neither PHA and androgen nor a trial with oxymetholone led to any haematological improvement. Complete recovery was observed in a patient in group 3, following a trial with oxymetholone.

1PHA, Burroughs Wellcome, England, 50-mg vials; Phyto PHA, Egic Laboratories, Loiret, France, $50-\mathrm{mg}$ vials.

\section{Discussion}

As can be seen from Tables 2, 3, and 4, there were great variations in both the clinical and haematological findings as well as in the state of the bone marrow in this series. Thus, the initial clinical conditions of the patients ranged from asymptomatic or mild forms to 'very severe', with a corresponding variation in the haematological picture. Yet the common basis in all our cases was two main features: (1) the presence of advanced and persistent pancytopenia, and (2) benzene as a causative agent. The mean age was lowest in group 3, which comprised patients with normoplastic bone marrows. In this group, the illness was less severe and the outcome more favourable than in the patients of the other groups. As there was no significant difference in the duration of exposure in all groups, we have the impression that older patients are more severely affected by chronic benzene exposure.

The clinical manifestations in our 32 pancytopenic patients were not different from those encountered in chronic benzene poisoning (Browning, 1965). As can be seen from Table 2, the great majority of clinical symptoms, such as bleeding and fever, etc., were mostly encountered in the patients with either hypoplastic or hyperplastic bone marrows. On the other hand, in the patients with a normoplastic bone marrow, similar clinical findings were not present. One interesting clinical manifestation was the haematological pleurisy or haemothorax due to thrombocytopenia in two patients. These rare complications of thrombocytopenia were the cause of death in one patient.

\section{Splenomegaly}

This was observed during the course of illness in two of the patients who died. In one of them, a splenic puncture was not done and a necropsy was refused, so the cause was not discovered. The possibilities of a leukaemic involvement or myeloid metaplasia cannot be excluded. The other patient, from group 4, exhibited a different picture because the hepatosplenomegaly, which developed five months before death, in association with the presence of numerous giant erythroid precursors in the bone marrow, was suggestive of preleukaemia.

\section{RBC and signs of increased haemolysis}

Anaemia was normocytic in 18 and macrocytic in 14 patients. The majority of patients with macrocytic anaemia were in group 2, with hyperplastic bone marrow. In two patients (one each in groups 2 and 4) the mean corpuscular volume was more than $114 \mu \mathrm{m}^{3}$. As expected, the bone marrow of both these patients also showed megaloblastic erythropoiesis.

A mild reticulocytosis was found in 16 and a mild hyperbilirubinaemia in 8 out of 28 patients. 
In addition, a marked increase in the excretion of faecal urobilinogen was observed in 9 out of 17 patients and a mild or moderate increase in osmotic fragility, before or after incubation, in 13 out of the 20 patients in whom this was studied. These four laboratory findings may be explained either by the presence of a haemolytic component (Goldwater, 1941; Scott, Cartwright, and Wintrobe, 1959; Erf and Rhoads, 1939; Aksoy et al., 1966) or by ineffective erythropoiesis which may be present in refractory anaemias (Barrett, Cline, and Berlin, 1966; Heller and Fried, 1967; Wintrobe, 1967).

Similarly, the mild erythroblastaemia, ranging between 1 and 8 per 100 WBC, which was mostly observed in group 2, may also be attributed to increased haemolysis or to the presence of ineffective erythropoiesis. In one of these six patients with erythroblastaemia in group 2 , this finding may also be explained by folic acid deficiency. In that patient, in whom there were 8 to 30 nucleated red cells per $100 \mathrm{WBC}$ in peripheral blood, adequate doses of folic acid caused a gradual disappearance of erythroblastaemia.

\section{Platelets}

In four patients, three with a hypoplastic and one with a normoplastic bone marrow, the platelet levels were within normal limits. Yet, in one of them, the platelet counts were always normal during a oneyear period of follow-up. Thus, considering the results obtained from these four patients and the results of a survey on 217 workers with long-term exposure to benzene (Aksoy et al., 1971a), we would suggest that megakaryocytes are more resistant to benzene than the precursors of granulocytic elements. Individual susceptibility should also be considered.

\section{Fetal haemoglobin}

According to Bloom and Diamond (1968), when the total fetal haemoglobin is less than $400 \mathrm{mg} / 100 \mathrm{ml}$, the prognosis of aplastic anaemia is unfavourable. There were 16 patients with total fetal haemoglobin less than $400 \mathrm{mg} / 100 \mathrm{ml}$, three in group 1, five in group 2, and eight in group 3. They all recovered. It is noteworthy that in 12 out of these 16 patients, the initial haematological state was severe. Thus, we suggest that in pancytopenic patients exposed to benzene, the total fetal haemoglobin value does not have the same prognostic value, as suggested by Bloom and Diamond (1968), in aplastic anaemia. This point has also been emphasized by Aksoy, Dinçol, Erdem, and Akgün (1969) and by Storti, Perugini, Massini, and Manzini (1969) in patients with aplastic anaemia due to various causes.

Shahidi, Gerald, and Diamond (1962) and Aksoy and Seçer (1964) have pointed out that the production of fetal haemoglobin to excess is 'switched on' in aplastic anaemia and overproduction continues well beyond recovery. In several patients, elevated levels of fetal haemoglobin persisted for many years after recovery. Sometimes it rapidly returns to normal. This happened in one patient in group 3, in whom, after complete recovery, the fetal haemoglobin content rapidly dropped from $19 \cdot 5$ to $2 \%$. On the other hand, occasionally the mechanism is 'switched on' a little late. In one patient, in group 3, the fetal haemoglobin was within normal limits when she was first seen. After the end of exposure, three months after recovery, the fetal haemoglobin was found to be $\mathbf{8 . 7 \%}$ and peripheral blood counts were within normal limits.

\section{Pelger-Huet anomaly}

In one patient, this leucocyte anomaly was detected following complete recovery. An incomplete family study did not confirm this inherited leucocyte anomaly, but the persistence of this finding two and a half years following his complete recovery is strongly in favour of a true Pelger-Huet anomaly. Interestingly, this pancytopenic patient with a Pelger-Huet anomaly showed a rapid clinical and haematological recovery. This prompted us to accept the possibility that such a congenital anomaly does not aggravate the haematological effects of chronic benzene poisoning.

\section{Bone marrow}

A maturation arrest in the granulocytic and erythroid series and an erythroid hyperplasia were the most commonly encountered findings in our pancytopenic patients with long-term exposure to benzene. Megaloblastic erythropoiesis in refractory anaemia with a hyperplastic bone marrow is considered to be due to a block in nucleoprotein formation (Vilter et al., 1960). Furthermore, folic acid deficiency may also play a role in the development of megaloblastic erythropoiesis observed in some pancytopenic patients exposed to benzene. In the patient in group 4 , the low level of serum folic acid ${ }^{1}$ confirmed this possibility. However, an unfavourable response to folic acid showed that folic acid deficiency was not the only factor in the development of a megaloblastic erythropoiesis in that patient. Furthermore, in another patient, in group 2, with megaloblastic erythropoiesis, the disappearance of a marked erythroblastaemia after folic acid therapy may be considered as confirmation of a folic acid deficiency although the folic acid level was not determined. Thus, in the development of megaloblastic erythropoiesis in the patients exposed to benzene, at least two factors may play a role: $(a)$ a block in the nucleoprotein formation, and (b) folic acid deficiency.

${ }^{1}$ Kindly performed by Dr. I. Chanarin, Experimental Haematology Research Unit, London. 


\section{Giant erythroid precursors}

In two patients (one in group 2 and one in group 4), giant erythroid precursors which were found to vary between 9 and $72 \%$ of nucleated cells were similar to those described by Mallory, Gall, and Brickley (1939) and erythrogones observed by Moeschlin and Speck (1967) in animals experimentally poisoned by the injections of benzene.

Leukaemia may appear in patients with aplastic anaemia due to chronic benzene exposure (Vigliani and Saita, 1964; Browning, 1965; Hernberg, Savilahti, Ahlman, and Asp, 1966). Four such cases were detected in our study among benzene workers (Aksoy, Dinçol, Erdem, and Dinçol, 1971b). It thus seems probable that the presence of giant erythroid precursors, which are usually very primitive cells with bizarre shapes, may be a feature of preleukaemia. This is a possibility in our one case in group 4

\section{Outcome}

The overall mortality in our series was $25 \%$. On the other hand, when the mortality rates of each group were considered separately, it became apparent that the rate was higher in group 1 than in groups 2 and 3 , being $41 \%, 28.5 \%$, and nil respectively. Furthermore, the mean age of eight patients who died is significantly higher $(P<0.01)$ than the mean age of the 19 who recovered completely. Older patients seem more likely to succumb to the deleterious effects of chronic benzene exposure.

\section{Treatment}

Because of the differences in the severity of the disease and the type of cellularity of the bone marrow in the patients in this series, it is difficult to evaluate the therapeutic results of this trial. However, we should stress that, in our experience, PHA may occasionally prove beneficial (Aksoy et al., 1969). This was observed in four patients (two in group 1, one in group 2, and one in group 3 ) who had previously been treated without improvement with steroids and androgens or with androgens alone. It was only after the administration of PHA that a considerable improvement was observed.

This study was supported by grant TAG/99 from the Scientific and Technical Council of Turkey.

\section{References}

Aksoy, M., Dinçol, K., Erdem, S., and Akgün, T. (1969)The results obtained from a triple treatment with androgens, steroids and phytohaemagglutinin of aplastic anaemia of various aetiology with emphasis on the prognostic value of total fetal haemoglobin content and bone marrow cellularity. Vth Congr. Asian Pacific Soc. Haemat. Abstract Book September 1-6, Istanbul, pp. 31-32.
,,--- , and Dinçol, G. (1971b). Acute leukaemia due to chronic benzene exposure. A study of three patients with acute myeloblastic and one arute monocytic leukaemia presenting with thrombocythemia as a finding of pre-leukemic stage. Amer. J. Med., in press.

- and Erdem, S. (1965). A simple method for the quantitation of haemoglobin $\mathbf{A}_{2}$ by starch gel electrophoresis. Clin. chim. Acta, 12, 696-698.

__, Erdem, S., Akgün, T., Okur, Ö., and Dinçol, K. (1966). Osmotic fragility studies in three patients with aplastic anaemia due to chronic benzene poisoning. Blut, 13, $85-90$.

- Erdem, S., and Dinçol, G. (1971a). The haematologic effects of chronic benzene poisoning in 217 workers. Brit. J. industr. Med., 28, 296-302.

- , and Seçer, F. (1964). Fetal hemoglobin in acquired aplastic anaemia. Acta haemat. (Basel), 32, 188-192.

Barrett, P. V. D., Cline, M. J., and Berlin, N. I. (1966). The association of the urobilin 'early peak' and erythropoiesis in man. J. clin. Invest., 45, 1657-1667.

Bloom, G. E., and Diamond, L. K. (1968). Prognostic value of fetal haemoglobin levels in acquired aplastic anaemia. New Engl. J. Med., 278, 304-307.

Brecher, G., and Cronkite, E. P. (1950). Morphology and enumeration of human blood platelets. J. appl. Physiol., 3, 365-377.

Browning, E. (1965). Toxicity and Metabolism of Industrial Solvents, p. 3. Elsevier, Amsterdam.

Dacie, J. V. (1960). The Haemolytic Anaemias, Congenital and Acquired, Part I. The Congenital Anaemias, 2nd ed., p. 96. Churchill, London.

Erf, L. A., and Rhoads, C. P. (1939). The haematological effects of benzene (benzol) poisoning. J. industr. Hyg., 21, 421-435.

Gadsden, R. H., and Cannon, A. (1964). Measurement of erythrocyte glucose-6-phosphate dehydrogenase activity. In: Haemoglobin. Its Precursors and Metabolites, edited by F. W. Sunderman and F. W. Sunderman, Jr., pp. 332336. Lippincott, Philadelphia.

Goldwater, L. J. (1941). Disturbances in the blood following exposure to benzol. J. Lab. clin. Med., 26, 957-973.

Heller, P., and Fried, W. (1967). Refractory anemias. Disease-a-Month, p. 3.

Hernberg, S., Savilahti, K., Ahlman, K., and Asp, J. (1966). Prognostic aspects of benzene poisoning. Brit. J. Industr. Med., 23, 204-209.

Huisman, T. H. J., and Dozy, A. M. (1961). Quantitative determination of the minor hemoglobin component $\mathrm{Hb}-\mathrm{A}_{2}$ by DEAE-cellulose chromatography. Analyt. Chem., 2, 400-403.

Mallory, T. B., Gall, E. A., and Brickley, W. J. (1939). Chronic exposure to benzene (benzol). III. The pathologic results. J. industr. Hyg., 21, 355-377.

Moeschlin, S., and Speck, B. (1967). Experimental studies on the mechanism of action of benzene on the bone marrow (radioautographic studies using 3H-thymidine. Acta haemat. (Basel), 38, 104-111.

Scott, J. L., Cartwright, G. E., and Wintrobe, M. M. (1959). Acquired aplastic anaemia. An analysis of thirty-nine cases and review of the pertinent literature. Medicine (Baltimore), 38, 119-172.

Shahidi, N. T., Gerald, P. S., and Diamond, L. K. (1962). Alkali resistant hemoglobin in aplastic anemia of both acquired and congenital types. New Engl. J. Med., 266, 117-120.

Singer, K., Chernoff, A. I., and Singer, L. (1951). Studies on abnormal haemoglobins. I. Their demonstration in sickle cell anaemia and other haematologic disorders by means of alkali denaturation. Blood, 6, 413-428.

Storti, E., Perugini, S., Mussini, C., and Manzini, E. (1969). 
Comportamento della emoglobina fetale nelle mielopatie involutive e suo interesse prognostico. In Le Mielopatie Involutive, p. 426. Pozzi, Roma.

Tönz, O., and Betke, K. (1962). Eifacher Farbsest zur Bestimmung der Glucose-6-Phosphatdehydrogenase Erythrocyten. Modification des 'Motulsky' testes. Klin. Wchschr., 40, 649-653.

Vigliani, E. C., and Saita, G. (1964). Benzene and leukemia. New Engl. J. Med., 271, 272-276.

Vilter, R. W., Jarrold, T., Will, J. J., Mueller, J. F., Friedman, B. I., and Hawkins, V. R. (1960). Refractory anemia with hyperplastic bone marrow. Blood, 15, 1-29. Wintrobe, M. M. (1967). Clinical Hematology, 6th ed., pp. $170,186,552,806,980$. Lea and Febiger, Philadelphia.

Wroblewski, F., and LaDue, J. S. (1955). Lactate dehydrogenase activity in blood. Proc. Soc. exp. Biol. (N.Y.), 90, 210-213.

Young, L. E., Davis, R. W., and Hogestyn, J. (1949). Simplified equipment for determination of urobilinogen in urine and stool. J. Lab. clin. Med., 34, 287-291.

Received for publication March 15, 1971 